\title{
Distal Interphalangeal Joint 5 of the Hand
}

National Cancer Institute

\section{Source}

National Cancer Institute. Distal Interphalangeal Joint 5 of the Hand. NCI Thesaurus.

Code C114274.

A ginglymoid (hinge) synovial joint within the fifth digit of the hand connecting the middle and distal phalanges. 